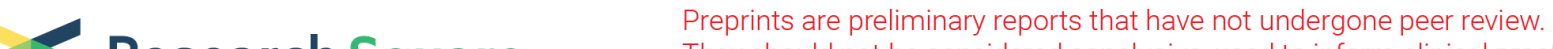 Research Square They should not be considered conclusive, used to inform clinical practice, or referenced by the media as validated information.
}

\section{Two Agrobacterium-mediated Transformation Protocols of White Clover (Trifolium Repens) Through the Callus System}

\section{Tong Jia}

Sichuan Agricultural University - Chengdu Campus https://orcid.org/0000-0003-1565-5600

\section{Bizhen Cheng}

Sichuan Agricultural University - Chengdu Campus

Huahao Feng

Sichuan Agricultural University - Chengdu Campus

Muhammad Jawad Hassan

Sichuan Agricultural University - Chengdu Campus

\section{Muhammad Zafar lqbal}

Sichuan Agricultural University - Chengdu Campus

\section{Zhou Li}

Sichuan Agricultural University - Chengdu Campus

\section{Shiqie Bai}

Sichuan Academy of Grassland Science

Yan Peng ( $\nabla$ pengyanlee@163.com )

Sichuan Agricultural University - Chengdu Campus https://orcid.org/0000-0001-7776-877X

\section{Research Article}

Keywords: white clover, callus, regeneration, transient transformation, Agrobacterium-mediated transformation

Posted Date: January 10th, 2022

DOI: https://doi.org/10.21203/rs.3.rs-1232094/v1

License: (c) (i) This work is licensed under a Creative Commons Attribution 4.0 International License. Read Full License 


\section{Abstract}

White clover (Trifolium repens) is one of the most widely cultivated livestock forage legumes cocultivated worldwide with pasture grass in a mixed-sward setting, however, its persistence and aesthetic quality are severely affected by abiotic stresses. In this study, regeneration of white clover plants was conducted through a callus system for 4-5 months with a regeneration frequency of $36-41 \%$. Inoculating 4-day-old cotyledons into MS media fortified with $0.4 \mathrm{mg} \cdot \mathrm{L}^{-1}$ 6-BA and $2 \mathrm{mg} \cdot \mathrm{L}^{-1}$ 2,4-D significantly increased the callus formation rate. Roots and cotyledons were better induced, followed by hypocotyls, leaves, and petioles. The development of differentiated structures performed effectively on MS supplemented with $1 \mathrm{mg} \cdot \mathrm{L}^{-1}$ 6-BA and $0.1 \mathrm{mg} \cdot \mathrm{L}^{-1} \mathrm{NAA}$. Further, we determined factors affecting the Agrobacterium tumefaciens-mediated transient transformation for root-derived callus and 4-day-old cotyledons. The parameters that facilitated transient transformation were: Agrobacterium suspension density of 0.5 (OD600), $20 \mathrm{mg} \cdot \mathrm{L}^{-1} \mathrm{AS}$, and 4-days co-cultivation duration. Subsequently, we developed two transformation protocols: transformation after callus formation in root segments (Protocol $A$ ) and transformation before callus initiation in 4-day-old cotyledons (Protocol B). The transformation frequencies varied from $1.92 \%$ to $3.17 \%$ in Protocol A and from $2.76 \%$ to $3.47 \%$ in Protocol B. We offer the possibility to regenerate multiple transgenic white clover from a single genetic background. In addition to assistance in identification of functional genes associated with yield, resistance and aesthetic quality, our research will also contribute to successful genetic manipulation and genome editing in white clover.

\section{Key Message}

This study achieved two Agrobacterium-mediated transformation protocols for white clover by the callus system, offering the possibility of regenerating the transgenic white clover with a single genetic background.

\section{Introduction}

White clover (Trifolium repens) is one of the most important low-growing perennial stoloniferous legume species distributed extensively in landscape and pasture systems all over the world. Due to its excellent nitrogen $(\mathrm{N})$ fixation potential, it is highly adapted to a wide range of low-maintenance turfgrass conditions (McCurdy et al. 2013). The addition of white clover to lawn mixtures has boosted the visual appeal, greenness, and expanded groundcover, hence contributing towards enhanced aesthetic value of landscapes (Sincik and Acikgoz 2007). White clover is highly palatable, nutritionally rich and possess sufficient protein content, thus plays an imperative role in improving pastures quality underpinning livestock production globally (Vaseva et al. 2011). However, the increased incidences of adverse environmental effects such as extreme temperatures, flooding, salinity, and drought have significantly reduced yields and aesthetic quality of white clover in the past few years (Jahufer et al. 2012; Williams et al. 2019). 
Along with the application of traditional breeding methods, the development of genetically modified white clover for better adaptability offers a fundamental way to overcome such shortcomings. With the availability of the whole genome for white clover (Griffiths et al. 2019), the effective use of genomic information will facilitate functional genomics research and promote the interface between conventional and genomic breeding. However, despite the global importance of white clover, it has remained behind other major pastures primarily Medicago sativa (Jiang et al. 2019; Kumar et al. 2018) in developing genomic tools for its improvement. Most functional genomic researches in white clover typically relied on heterologous expression, depending on the Arabidopsis or Medicago truncatula as the model plant (Forster et al. 2013). Therefore, it is still important to develop a highly reproducible and widely applicable transformation system to benefit the white clover transformation network.

White clover callus was established for the first time by culturing 2-day-old clover germlings on induction media with a 50:1 auxin to cytokinin (w/w) ratio (Oswald et al. 1977). Subsequently, successful plant regeneration occurred from callus and suspension cultures (Gresshoff 1980; White 1984; Yamada 1989). Approximately two-third of early investigations addressed aspects of suspension cultures and mesophyll protoplast procedures (Ahuja et al. 1983; Bhojwani and White 1982; Mohapatra and Gresshoff 1982; Parrott and Collins 1983; Webb et al. 1987), which might be the result of large populations they provide. However, producing numerous suspension cells might increase the complexity of the regeneration process and the incidence of phenotypic and genotypic variations for white clover (Pederson 1986; Webb et al. 1987). Also, may not be suitable for some simple laboratory conditions.

The first successful genetic transformation of white clover was carried out in 1987 based on cell suspension cultures using a high-regenerating genotype WR8 (White and Greenwood 1987). Nonetheless, the frequency of that Agrobacterium tumefaciens-mediated transformation system was extremely low $(<1 \%)$ because of the complex medium compositions and laborious procedures of callus induction and suspension incubation. Only a few reports (Ealing et al. 1994; Voisey et al. 1993) have followed this protocol. In 1994, a procedure was established to regenerate white clover shoots directly and rapidly from cotyledon petioles of 3-day-old seedlings (White and Voisey 1994). After that, a transformation method procedure following shoot organogenesis was described using Agrobacterium tumefaciens strain LBA4404 as a carrier, but the transformation frequency was less than 1\% (Voisey et al. 1994). Meanwhile, several studies have been reported based on this protocol (Christiansen et al. 2000; Ding et al. 2003; Islam et al. 2015; Jenkins et al. 2002; Larkin et al. 1996; Mcmanus et al. 2005; Narancio et al. 2020; Schmidt et al. 2004). As white clover is an obligate outcrossing plant, hence each seed represents a distinct genotype. Although plants obtained by organogenic regeneration from cotyledons may contain the same T-DNA, yet each plant processes heterozygous chromosomal backgrounds. A split cotyledon approach where cotyledon pairs are tracked (one transformed and the other not) is the only method currently available to compare transformed and non-transformed plants with isogenic genetic backgrounds, but this is an incredibly tedious and time-consuming process.

To address some of these shortcomings, we successfully reproduced white clover plantlets from calluses in the current study and obtained a regeneration frequency between $36 \%$ and $41 \%$, which allows the 
generation of multiple plants from a single genetic background. In addition, to develop an appropriate transformation system, we modified this system and implemented two protocols for Agrobacteriummediated transformation (Protocol A and Protocol B). Our research is of great significance for the improvement of the white clover transformation network.

\section{Material And Methods}

\section{Plant material}

Seeds of white clover (Trifolium repens $\mathrm{cv}$. Ladino) were used for regeneration and transformations. Seeds were superficially sterilized with ethanol $(70 \%, v / v)$ for 5 min followed by 10 min in $\mathrm{HgCl}_{2}$ solution $(0.1 \%, w / v)$ and washed five times with sterile distilled water. Subsequently, seeds were scattered on filter paper to germinate for 4 days and kept on MS medium (Murashige and Skoog 1962) to grow for 30 days. The attained seedlings or aseptic plantlets were selected for inoculation. The plantlets were maintained in controlled environment of growth chambers at $24 / 22^{\circ} \mathrm{C}$ day/night temperature, $16 \mathrm{~h} / 8 \mathrm{~h}$ light/dark cycle, and light intensity of $150 \mu \mathrm{mol} \mathrm{m}^{-2} \mathrm{~s}^{-1}$, respectively

\section{Callus induction and regeneration}

The cotyledons, hypocotyls, roots, leaves, and petioles were used as explants for callus induction. Briefly, cotyledons, hypocotyls, and roots were taken from germinated 4-day-old sterile seedlings. The cotyledons were dissected into 2-3 sections, and the hypocotyls and roots were cut cross-sectionally into 2-3 mm long longitudinal segments (Supplementary Material: Fig. S1A and S1B). The petioles of 30-day-old aseptic plantlets were excised into 3-4 mm fragments, and the leaves were divided into 3-4 parts (Supplementary Material: Fig. S1C and S1D).

The cotyledon sections were taken as explants to determine the hormonal ratios for callus induction. The callus tissues were induced on the MS basal medium containing different concentrations of 2,4dichlorophenoxy acetic acid (2,4-D; 1, 2, 3, $\left.5 \mathrm{mg} \cdot \mathrm{L}^{-1}\right)$ and $0.4 \mathrm{mg} \cdot \mathrm{L}^{-1}$ 6-benzyl amino purine (6-BA). The composition of the media is shown in Supplementary Material: Table S1. Furthermore, the $\mathrm{pH}$ of the media was adjusted to 5.8 before autoclaving at $121^{\circ} \mathrm{C}$. The explants were initially grown in the dark for 20 days, and initiation efficiency was counted after cultivation on various clover callus mediums (CCM1CCM5). Calluses were then sub-cultured after every 20 days on fresh medium. Callus browning rate, callus thickness, and callus area were measured at the 25th day of sub-culturing.

To examine the callus formation effect, the cotyledons, hypocotyls, roots, leaves, and petioles were inoculated into CCM2 containing $2 \mathrm{mg} \cdot \mathrm{L}^{-1} 2,4-\mathrm{D}$ and $0.4 \mathrm{mg} \cdot \mathrm{L}^{-1} 6-\mathrm{BA}$. The whole process of callus induction was accomplished in a dark environment. Each medium and explant type was subjected to three independent experiment replicates (60 tissues per set of experiments).

60-day-old fresh embryogenic callus differentiation was tested on MS media supplemented with

naphthalene acetic acid (NAA; $\left.0.1 \mathrm{mg} \cdot \mathrm{L}^{-1}\right)$ and disparate quantities of $6-\mathrm{BA}\left(0.5,1,1.5,2 \mathrm{mg} \cdot \mathrm{L}^{-1}\right)$. 
Supplementary Material: Table S2 shows the combinations of different clover differentiation mediums (CDM1-CDM4). Each concentration was verified with three replicates of about 150 calluses. Regenerated shoots and embryoids were cultivated on MS medium containing $0.1 \mathrm{mg} / \mathrm{L}$ NAA (clover rooting medium, CRM) (Ahuja et al. 1983) for root development under growth chamber at $23^{\circ} \mathrm{C}$ with a $16 \mathrm{~h} / 8 \mathrm{~h}$ light/dark photoperiod.

Agrobacterium tumefaciens strain and plasmid vectors

The binary plasmid PBI121 (Gene Bank accession: AF485783.1), carrier of the neomycin phosphotransferase II (NPTII) and the $\beta$-glucuronidase (GUS) reporter gene, was applied for transformation. PBI121 vector was introduced into white clover tissues using the Agrobacterium tumefaciens strain EHA105 (Hood et al. 1993) containing a disarmed Ti plasmid. Single colonies of Agrobacterium EHA105 were incubated in $50 \mathrm{ml}$ of YEB liquid medium with $20 \mathrm{mg} \cdot \mathrm{L}^{-1}$ rifampicin (Rif) and $50 \mathrm{mg} \cdot \mathrm{L}^{-1}$ kanamycin (Kan) at $28^{\circ} \mathrm{C}$, and shaken at $180 \mathrm{rpm}$ for $65 \mathrm{~h}$.

\section{Agrobacterium -mediated white clover transient transformation}

To evaluate the efficiency of Agrobacterium-mediated transient transformation, cotyledons explants and 60-day-old calluses were infected with the Agrobacterium suspension. The treatments were as follows: (1) Agrobacterium bacteria were suspended in liquid clover infection mediums (CIM) supplemented with $10 \mathrm{mg} \cdot \mathrm{L}^{-1}$ acetosyringone (AS). The optical density at $600 \mathrm{~nm}(\mathrm{OD} 600)$ was adjusted to $0.1,0.2,0.3,0.5$, and 0.7 , respectively. Tissues were placed in the suspended solutions for $20 \mathrm{~min}$ and incubated on the cocultivation medium (CM) for 3 days at $22^{\circ} \mathrm{C}$. (2) Agrobacterium cells were resuspended to an OD600 of 0.3 and added with $0,10,20$, or $40 \mathrm{mg} \cdot \mathrm{L}^{-1} \mathrm{AS}$, respectively. Tissues were immersed in suspension for 20 min and cultivated on CM for 3 days. (3) Following 20 min infection in CIM (OD600=0.3) containing 20 $\mathrm{mg} \cdot \mathrm{L}^{-1} \mathrm{AS}$, tissues were dried on sterile filter paper to remove excessive Agrobacterium and co-cultured on $\mathrm{CM}$ in dark conditions for 1-5 days. These tissues were stained daily with 5-bromo-4-chloro-3-indolylglucuronide (X-Gluc) after being co-cultivated on CM.

Two protocols of Agrobacterium tumefaciens-mediated white clover transformation and plant regeneration

\section{Protocol A: Agrobacterium-mediated transformation in white clover 'Ladino' after callus formation from 4- day-old roots}

Root explants of 4-day-old white clover 'Ladino' seedlings were placed on CCM2 and cultured at $22^{\circ} \mathrm{C}$ in a dark environment. After 40-50 days, the callus was formed and utilized for transformation. The Agrobacterium bacteria was centrifugally agglomerated for $20 \mathrm{~min}$ at $4500 \mathrm{rpm}$ on the date of transformation. The supernatant was thrown out, and the cells were delicately resuspended in liquid CIM1 with $20 \mathrm{mg} \cdot \mathrm{L}^{-1} \mathrm{AS}$ and $600 \mathrm{mg} \cdot \mathrm{L}^{-1}$ casein peptone at an optical density of $0.5(600 \mathrm{~nm})$. Uniform readyto-infection calluses were collected in CIM1 and gently agitated $(80 \mathrm{rpm})$ for $20-25 \mathrm{~min}$ at $28^{\circ} \mathrm{C}$. Following infection, the callus was laid on sterile filter paper to absorb excessive suspension. After co- 
cultivation with adhering Agrobacterium for 4 days on CM1, the callus was washed 3-4 times with distilled water. The calluses were then sub-cultured under a $16 \mathrm{~h}$ photoperiod on CDM2 selection medium (CDM2-S) containing $50 \mathrm{mg} \cdot \mathrm{L}^{-1}$ Kan to select transformed cells and $300 \mathrm{mg} \cdot \mathrm{L}^{-1}$ Cefotaxime sodium salt (Cef) to inhibit the further growth of $A$. tumefaciens. After 20 days, the resistant green shoot buds and embryoids of Kan were transferred to the same CDM2-S media for an additional 20-40 days to develop shoots. Regenerated green shoots under Kan selection were then placed on CRM selection medium (CRMS) at $23^{\circ} \mathrm{C}$ on a $16 \mathrm{~h} / 8 \mathrm{~h}$ light/dark photoperiod for whole-plant development. After roots formation within 30-40 days, the regenerated plantlets were transplanted in the soil. The composition of the media for Protocol A has been given in Supplementary Material: Table S3.

\section{Protocol B: Agrobacterium-mediated transformation in 'Ladino' clover before callus initiation from cotyledons}

Cotyledons explants from 4-day-old white clover 'Ladino' seedlings were immersed in liquid CIM2 supplemented with $A$. tumefaciens $(\mathrm{OD} 600=0.5)$ and then incubated at $28^{\circ} \mathrm{C}$ for $20-25 \mathrm{~min}$ at $80-100$ rpm. Subsequently, the explants were dried on sterile filter paper and co-cultivated with Agrobacterium on $\mathrm{CM} 2$ at $23^{\circ} \mathrm{C}$ for 4 days. After washing 3-4 times with sterile water, the explants were transferred to CCM2 selection medium (CCM2-S) supplemented with $300 \mathrm{mg} \cdot \mathrm{L}^{-1}$ Cef and $50 \mathrm{mg} \cdot \mathrm{L}^{-1} \mathrm{Kan}$ and incubated at $23^{\circ} \mathrm{C}$. The selection was implemented in the dark for 50-60 day with media alteration after every 20 days. The differentiated structure induction and roots development procedure were the same as described in protocol A on CDM2-S and CRM-S medium, under a $16 \mathrm{~h} / 8 \mathrm{~h}$ light/dark photoperiod at $23^{\circ} \mathrm{C}$. The green-

white clover plantlets were transferred into the greenhouse about 40 days after root formation. The media composition for Protocol B has been shown in Supplementary Material: Table S4.

\section{Identification of transformed explants or plants}

Genomic DNA, extracted from putative transgenic plants surviving under Kan selection, was amplified by PCR using the selectable marker NPTI/ sequence region and primers sequences were $5^{\prime}$ -

GAGGCTATTCGGCTATGACTGG-3' and 5'-ATCGGGAGCGGCGATACCGTA-3', respectively (Hamama et al. 2011). White clover plants with positive PCR amplification for the marker gene sequence were considered as transgenic white clover.

For histochemical GUS staining analysis, various tissues of explants or transgenic seedlings were incubated in GUS staining buffer containing $0.1 \%(w / v)$ X-Gluc at $37^{\circ} \mathrm{C}$ for $12 \mathrm{~h}$. After staining, samples were decolorized with $70 \%$ alcohol.

\section{Statistical analysis}

The data were analyzed using SPSS 25.0 statistics and analysis software (IBM, Armonk, New York, USA). Following one-way ANOVA, in combination with Fischer's least significant difference (LSD) was used to test significant differences among treatments at a 0.05 probability level.

\section{Results}




\section{Callus initiation and formation in white clover}

To analyze the impact of various 2,4-D concentrations on induction and development of embryonic callus in white clover, cotyledons as explants were employed with MS medium as basal substrate with the addition of $0.4 \mathrm{mg} \cdot \mathrm{L}^{-1}$ 6-BA. Throughout the 45-day callus induction on CCM1-CCM5, there was an apparent naked eye evident difference in callus proliferation. Embryo-like structures were observed on MS media supplemented with 2,3 , and $5 \mathrm{mg} \cdot \mathrm{L}^{-1}$ 2,4-D under the microscope. As a whole, cotyledon-derived callus at $2 \mathrm{mg} \cdot \mathrm{L}^{-1}$ 2,4-D (CCM2) exhibited a better and greater embryogenic structure (Fig. 1A). Despite of more than $60 \%$ callus initiation efficiency under each medium variant, over $90 \%$ of callus initiated under 2 $\mathrm{mg} \cdot \mathrm{L}^{-1}$ and $3 \mathrm{mg} \cdot \mathrm{L}^{-1}$ 2,4-D after a 20-day induction phase (Fig. 1B). When sub-cultured for 25 days, callus browning rates were lowest at $2 \mathrm{mg} \cdot \mathrm{L}^{-1}$ compared to the rates observed at $1 \mathrm{mg} \cdot \mathrm{L}^{-1}$ and $5 \mathrm{mg} \cdot \mathrm{L}^{-1}$ 2,4-D (Fig. 1C). Also, the callus thickness and area were highest at $2 \mathrm{mg} \cdot \mathrm{L}^{-1}$ 2,4-D compared to other concentrations (Fig. 1D and $1 \mathrm{E}$ ). These results demonstrated that $\mathrm{MS}$ basal medium containing $2 \mathrm{mg} \cdot \mathrm{L}^{-1}$ 2,4-D and $0.4 \mathrm{mg} \cdot \mathrm{L}^{-1}$ 6-BA (CCM2) was more appropriate for callus initiation and proliferation in white clover cotyledons.

When inoculated on CCM2 medium, embryogenic calluses were obtained from the cotyledons, hypocotyls, roots, leaves, and petioles explants of white clover (Fig. 2A). Under the microscope, numerous pro-embryos or somatic embryos were visible on the surface of the embryogenic callus. Alternatively, a minute difference was found in callus initiation efficiency after 20-day induction (Fig. 2B). Compared to cotyledons, hypocotyls, roots, and leaves explants, over $30 \%$ of the petiole explants turned brown and died after 25-days of proliferation (Fig. 2C). More callus thickness and area were observed in roots and cotyledons explants than leaves explants (Fig. 2D and 2E). Overall, roots, and cotyledons explants were optimal for callus proliferation in white clover, followed by hypocotyls and leaves inoculated in MS media supplemented with $2 \mathrm{mg} \cdot \mathrm{L}^{-1}$ 2,4-D and $0.4 \mathrm{mg} \cdot \mathrm{L}^{-1}$ 6-BA. Moreover, petioles explants were inferior for callus formation on $\mathrm{CCM} 2$.

\section{Shoot induction and plant formation}

After 50-60 days of embryogenic callus formation, the callus was successively transferred into MS medium supplemented with $0.1 \mathrm{mg} \cdot \mathrm{L}^{-1} \mathrm{NAA}$ and varying quantities of $6-\mathrm{BA}\left(0.5,1,1.5,2 \mathrm{mg} \cdot \mathrm{L}^{-1}\right)$ at $23^{\circ} \mathrm{C}$ and a $16 \mathrm{~h} / 8 \mathrm{~h}$ light/dark photoperiod. Plenty of somatic embryos in the globular stage started greening after 7 days (Fig. 3A). Under the four applied mediums (CDM1-CDM4), partial calluses gradually browned from the periphery to the middle or hydrated without further differentiation. Even so, more than $50 \%$ of somatic embryos regenerated shoots under $1 \mathrm{mg} \cdot \mathrm{L}^{-1}$ 6-BA, compared with $27.5 \%$ and $35.7 \%$ under 0.5 $\mathrm{mg} \cdot \mathrm{L}^{-1}$ and $2 \mathrm{mg} \cdot \mathrm{L}^{-1} 6-\mathrm{BA}$, respectively (Fig. $3 \mathrm{~B}$ ). The regenerated white clover shoots were obtained after 50 days of shoot proliferation (Fig. $3 \mathrm{C}$ ). Subsequently, the regenerated shoots were transplanted to CRM added with $0.1 \mathrm{mg} \cdot \mathrm{L}^{-1} \mathrm{NAA}$ to stimulate rooting. Most shoots produced roots longer than $5 \mathrm{~cm}$ after 40 days of cultivation (Fig. 3D). Thus, $36 \%-41 \%$ of white clover plantlets were eventually regenerated from the callus system. 


\section{Comparison of the effect of critical factors on the transient transformation efficiency}

The impact of critical factors on transient transformation frequency was assessed after infection with $A$. tumefaciens EAH105. To determine optimum density for infected Agrobacterium cells, five different densities of Agrobacterium (OD600 ranging from 0.1 to 0.7 ) were prepared to infect tissues separately. After 20 min of infection at $10 \mathrm{mg} \cdot \mathrm{L}^{-1} \mathrm{AS}$, the highest number of positive GUS staining tissues was found at an OD600 of 0.5 (Fig. 4A). Additionally, the efficacy of the transformation level was significantly influenced by the AS concentration, with the highest efficiency of $78.83 \%$ (callus) and $78.68 \%$ (cotyledon) at $20 \mathrm{mg} \cdot \mathrm{L}^{-1}$ AS (Fig. 4B). Besides, the percentage of tissues displaying GUS staining frequency increased when the co-culture duration was prolonged (Fig. 4C), with five days of co-incubation manifesting the highest transient transformation efficiency. Since the extension in the co-cultivation time and increase in the Agrobacterium concentration, the GUS staining frequency enhanced progressively. Nonetheless, the excessive proliferation of Agrobacterium exceedingly triggered the wounded cells leading to serious tissue injury. Moreover, our findings indicated that Agrobacterium more readily infected calluses than cotyledons explants.

\section{Comparison of two Agrobacterium-mediated transformation protocols for callus}

In the present study, two transformation protocols related to white clover callus were carried out. Roots were the most desirable explants to proliferate callus, as aforementioned. Root-derived callus was transformed using the first method (Protocol A, Fig. 5A-C, F-J). Furthermore, the present experiment endeavored to transform root explants before callus initiation, but the root system proved to be fragile and caused numerous tissues damage after infection (Supplementary Material: Fig. S2A). In addition to cotyledons explants (Fig. 5E), hypocotyls, leaves, and petioles were also severely browned after infection (Supplementary Material: Fig. S2B, S2C, and S2D). Thus, cotyledons explants were adopted for Protocol $B$, in which callus was induced after transformation (Fig. 5D-F).

By the selection of Agrobacterium-infected tissues on CDM2-S, a partially pale green callus was observed as shown in (Fig. 5F). Observation of germinating embryos in a stereomicroscope confirmed that some embryos tuned green (transgenic) by the selection, while others were considered un-transgenic, which did not become green but turned yellow (Fig. 5G, 5H). During regeneration, both somatic embryogenesis and organogenesis occurred. Untransformed callus turned brown and died in a regular sub-culture on CDM2-

S. After three rounds of Kan antibiotic screening, the multiple green shoots survived (Fig. 5I, 5J), while the untransformed growth was bleached white. In two replicated experiments using Protocol A, 16 of 208 (7.69\%) and 21 of 189 (11.1\%) explants established resistance to Kan. On the other hand, $5.45 \%$ and $4.15 \%$ resistant shoots were regenerated by Protocol B (Table 1). 
Table 1

Comparison of transformation efficiency among three protocols

\begin{tabular}{|llllll|}
\hline Material/Method & $\begin{array}{l}\text { Experiment } \\
\text { /No. } \\
\text { Explants }\end{array}$ & $\begin{array}{l}\text { Kan- } \\
\text { Resistant } \\
\text { Shoots }\end{array}$ & $\begin{array}{l}\text { Kan- } \\
\text { resistant } \\
\text { plants }\end{array}$ & $\begin{array}{l}\text { Positive } \\
\text { lines/Negative lines } \\
\text { (PCR configuration) }\end{array}$ & $\begin{array}{l}\text { Transformation } \\
\text { Efficiency }\end{array}$ \\
\hline Protocol A & $1 / 208$ & $16(7.69 \%)$ & 9 & $4 / 5$ & $1.92 \%$ \\
\hline Protocol B & $2 / 189$ & $21(11.1 \%)$ & 10 & $6 / 4$ & $3.17 \%$ \\
& $1 / 202$ & $11(5.44 \%)$ & 9 & $7 / 2$ & $3.47 \%$ \\
\hline & $2 / 217$ & $9(4.14 \%)$ & 8 & $6 / 2$ & $2.76 \%$ \\
\hline
\end{tabular}

To ensure that all plants were independent transformants, only one resistant shoot from each callus was placed onto CRM-S (Fig. 5K). White clover roots germinated after approximately 40 days (Fig. 5L), and the transgenic white clover was subsequently transferred into the soil (Fig. 5M). It happened that some shoots failed to produce roots after several weeks on CRM-S. 19 and 17 Kan-resistant plantlets through Protocol A and Protocol B were eventually collected (Table 1). The formed transgenic plants displa

\section{Transgenic plants identification and Transformation efficiencies}

After transplanting the surviving plants into the soil, the regenerated plants were verified by PCR with vector-specific primers to investigate the presence of the NPTI/ gene for PBI121 (Fig. 7A). Furthermore, leaves and petioles of positive white clover were examined for the presence of histochemical GUS activity. Intensely stained leaves and petioles were visible from transgenic plants, implying the expression of the GUS reporter gene in tissues (Fig. 7B). After selection, $75 \%$ and $77.7 \%$ of resistant plants were positive by Protocol B, compared to $44.4 \%$ and $60 \%$ for Protocol A (Table 1). Plant transformation efficiency, in terms of the number of positive confirmed transgenic white clover produced per one hundred infected explants, ranged from $1.92 \%$ and $3.17 \%$ through Protocol $A$, and $2.76 \%$ and $3.47 \%$ through Protocol B.

\section{Discussion}

\section{Effect of medium and explants on callus induction}

Distinct basal culture media contains various organic components which perform vital roles in plant regeneration. Contrary to the results (Ahuja et al. 1983; Gresshoff 1980; Parrott and Collins 1983; White 1984) documenting incubation and plantlet regeneration on different substrate media: MS, Gamborg B5, Phillips and Collins L2, Schenk and Hildebrandt (SH), the present study utilized a single base medium (MS) during all the tissue culture phases to facilitate work in the laboratory, and only changed the growth regulator levels in MS. 
Previous studies have reported that the presence of 2,4-D is imperative in the process of somatic embryogenesis for white clover. White clover calluses have formed successfully under three combinations of hormone: 2,4-D + kinetin (KT) (Gresshoff 1980; White 1984), 2,4-D + NAA + KT (Pederson 1986), and 2,4,5-T + KT (Oswald et al. 1977). Nevertheless, few studies have also explored 6-BA's potential on the induction of white clover callus. Our findings showed that $0.4 \mathrm{mg} \cdot \mathrm{L}^{-1} 6-\mathrm{BA}$ plus relatively high levels of auxin, $2 \mathrm{mg} \cdot \mathrm{L}^{-1}$ and $3 \mathrm{mg} \cdot \mathrm{L}^{-1} 2,4-\mathrm{D}$, resulted in higher frequency of embryonic callus, implying that additional 6-BA also exhibits an inductive effect. However, the callus testified to have adverse changes with progressive increase in the concentration of 2,4-D. A review of the literatures concluded that the higher 2,4-D levels may interfere with somatic embryo development and disrupt the normal chromatin structure rearrangement, histone modification, and DNA methylation in plant cells (Garcia et al. 2019; Gresshoff 1980; Konieczny et al. 2012). Oswald H media supplemented with 2,4,5-T maintained viability and induced growth of white clover callus, suggesting that 2,4,5-T was a more suitable alternate auxin source than 2,4-D (Oswald et al. 1977). It remains to be investigated in our protocol, as we adapted different base media and hormone combinations.

Attention should not only be focused on the medium as the explant nature (tissue, organ, growth stage) is equally important in allowing successful initiation. Different plant tissues showed vast distinct callus induction frequencies (Gresshoff 1980; Karadotcheva et al. 1995). Even though cotyledons, hypocotyls, roots, leaves, and petioles explant initially expanded and proliferated callus on the cutting surface, however 4-day-old roots explants exhibited the highest induction capacity for forming embryo structures. Previous studies on root-derived calluses found similarities in morphology with different white clover ecotypes (Mohapatra and Gresshoff 1982; Parrott and Collins 1983). Following the observation of other ecotypes, our study identified that the developing Ladino root similarly produced a callus around mantle. In addition, 30-day-old leaves and petioles explants showed the highest brown discoloration than 4-dayold cotyledons, hypocotyls, and roots, manifesting the declined viability in mature explants.

\section{Shoot regeneration and plant recovery}

It has been determined that differentiation media containing 2,4-D formed many abnormal shoots, which could not sprout or grow slowly (Bond and Webb 1989). Thus, NAA was utilized as a possible alternate auxin source. 6-BA was once taken up as the component of exogenous hormones to ameliorate regeneration capacity for white clover (Ahuja et al. 1983; Webb et al. 1987; White 1984). Here, adding 1 $\mathrm{mg} \cdot \mathrm{L}^{-1} 6-\mathrm{BA}$ and $0.1 \mathrm{mg} \cdot \mathrm{L}^{-1} \mathrm{NAA}$ to $\mathrm{MS}$ effectively developed the de-differentiated structures into plants.

Many researchers have applied only regeneration media or hormone-free basal media to promote rooting (Bhojwani 1981; Oswald et al. 1977; Webb et al. 1987; Weissinger and Parrott 1993) indicating that white clover roots possess a powerful regeneration ability. NAA has been widely used to stimulate rhizogenesis in other plants (Amiri and Mohammadi 2021; Hansuek et al. 2018; Martins et al. 2020). Our study discovered that adding $0.1 \mathrm{mg} \cdot \mathrm{L}^{-1} \mathrm{NAA}$ extremely facilitated root primordia in the hypocotyl region of excised shoots, which was consistent with previous studies on white clover (Ahuja et al. 1983; Bond and Webb 1989). 


\section{Agrobacterium-mediated transient transformation}

Based on the data obtained from white clover regeneration research, our research attempted to deliver genes to white clover through the Agrobacterium-mediated transformation. The supplement of amino acid mixtures positively influenced the co-incubation of Agrobacterium and explants (Mukherjee et al. 2000; Zaidi et al. 2006). In this study, the liquid infection media and co-incubation medium have undergone certain modifications to contain $600 \mathrm{mg} \cdot \mathrm{L}^{-1}$ casein-hydrolysate as an additional ingredient. The Agrobacterium strains LBA4404 (Mcmanus et al. 2005; White and Greenwood 1987), AGL1 (Jenkins et al. 2002; Larkin et al. 1996), GV2260 (Schmidt et al. 2004), and CZ707 (Panter et al. 2012) have been applied for infecting white clover. The Agrobacterium EHA105 containing the hypervirulent Ti plasmid pTiBo542 (Hood et al. 1993) was utilized for transformation, which had previously been used to confer higher transformation efficiencies in many species (Arun et al. 2015; Benzle et al. 2015; Chetty et al. 2013).

Many factors contribute to the transformation efficiency of plants, however among those the most vital factor is the target material. Our study applied two types of target explants to inquire about the transient efficiency: root-derived callus and 4-day-old cotyledons. The tissues immersed in the Agrobacterium suspension with an OD600 of 0.5 and 0.7 showed higher Gus staining efficiency. Excessive levels of Agrobacterium could damage explants, causing them to be brown and dead. Alternatively, insufficient levels of Agrobacterium could result in low infection rates (Hayta et al. 2019). Consequently, we employed an Agrobacterium suspension with an OD600 of 0.5 for 20-25 min to carry out the infection. As a precursor of the plant cell wall, AS elicited the activation of the virulence genes and enhanced Agrobacterium infection in wound cells (Mo et al. 2015). Regarding the AS concentration, $20 \mathrm{mg} \cdot \mathrm{L}^{-1} \mathrm{AS}$ was applied in subsequent transformation as the transient transformation efficiency did not differ significantly between $20 \mathrm{mg} \cdot \mathrm{L}^{-1}$ and $30 \mathrm{mg} \cdot \mathrm{L}^{-1}$ in our study. Previous transformation protocols for white clover tissues indicated that co-cultivation of Agrobacterium with explants lasted three to five days (Christiansen et al. 2000; Larkin et al. 1996; Sharma et al. 1998; Voisey et al. 1994). In this study, the higher transient transformation efficiency occurred at four and five days. Nonetheless, considering that the overgrowth of Agrobacterium excessively triggered the tissues in the wound, thus 4-day co-cultivation duration was selected to be utilized in subsequent experiments.

\section{Comparison of two transformation protocols}

In this study, two protocols were introduced to transform white clover with distinct initial materials. Protocol A yielded $7.69 \%$ and $11.1 \%$ of Kan-resistant shoots in two treatments. In contrast, Protocol B produced fewer resistant shoots, indicating that fewer explants survived in the long-term selecting stages (3-4 months). A part of the initial resistant shoots was lost by extending selection time, of which the leaves turned yellow, or no root could be produced when grown on CRM-S. This phenomenon was particularly severe in Protocol A. Our results hypothesize that these shoots (escapes) were not transformants, but rather natural resistance within the early selecting stages of selection. 
An efficient selector can restrain un-transformed tissues proliferation and enable transformed cells growth. The Npt/l gene is the most widely applicable and confers antibiotic resistance such as Kan, neomycin, and G-418. $50 \mathrm{mg} \cdot \mathrm{L}^{-1}$ (Ding et al. 2003; Narancio et al. 2020) and $100 \mathrm{mg} \cdot \mathrm{L}^{-1}$ (Sharma et al. 1998; Voisey et al. 1994) Kan have been applied to inhibit the growth of non-transformed white clover

cells. $50 \mathrm{mg} \cdot \mathrm{L}^{-1}$ Kan was selected in the current study, as higher Kan concentrations may negatively influence organogenic potential and affect shoot and root regeneration. However, a high percentage of escapes were identified from putative transformants by PCR analysis. Protocol B has a higher positive rate than Protocol $\mathrm{A}$, which could be attributed to the more extended selection period. Thus, our findings suggest to maintain explants for additional 20-30 days on antibiotic selection for an augmented positive rate. This idea is consistent with the previous works (Hayta et al. 2018; Larkin et al. 1996).

In the present study, Protocol A and Protocol B took 4-5 months to produce transgenics from the initial plant material. Although Protocol A and Protocol B required relatively similar times, callus can be maintained undifferentiated at least for 5 months in Protocol A. Therefore, it is possible to reduce the transformation time to 3-4 months using the preserved callus for future transformations. Also, multiple plants could be regenerated from a single genetic background through sub-culturing calluses. Protocol B is a rapid method but has tremendous potential for regenerating partially transformed plants (chimeras). Our findings suggest that this approach be applied in early functional genetic assays to permit rapid gene characterization at relatively lower input. According to the required operation procedure, time, and labor, researchers can choose any of our two protocols that best fit their needs.

Previous studies have pointed out that phosphinothricin (PPT) selection (phosphinothricin acety/transferase gene, Bar) brought more stringent and rapid selection than Kan selection (Larkin et al. 1996; Wen et al. 2019), and the efficiency of transgenic recovery using PPT was superior when compared with Kan (RamanaRao and Veluthambi 2010). We need to spend more labor and time to monitor the white clover tissue constantly, though some white clover escapes and chimeras died during the long period of Kan selection. The green fluorescent protein (GFP) signals can be visualized at an early stage, allowing more convenient examination than histochemical GUS staining and eliminating the waste of plant material. Therefore, to optimize the current transformation process, we constructed a binary vector PmI-CAMBIA3300-35S-EGFP, which carries a chimeric Bargene and an EGFP gene driven by CaMV 35S promoter (Supplementary Material: Fig. S3), for future transformation experiments. Nevertheless, whether the alternate binary vector can facilitate the procedures and improve frequency remains to be verified. Also, we are conducting experiments to reduce the browning rate of the transformed leaf and petiole explants. Thus, we expect to use only one white clover plantlet through protocol $B$, which will enable us to obtained transgenic plants with a single genetic background.

\section{Conclusion}

The current work demonstrated callus culture conditions and somatic embryogenesis regeneration using different hormone concentrations and various explants for white clover 'Ladino', with a regeneration frequency between $36 \%$ and $41 \%$. Establishing an effective and stable genetic transformation system is a 
pre-requisite for selecting a wide variety of genetically modified plants. As the preparation for further Agrobacterium-mediated transformation, the present study evaluated the impacts of Agrobacterium densities, AS concentrations, and co-cultivation durations on the effectiveness of transient transformation. Besides, the current research achieved two transformation protocols (Protocol $A$ and Protocol B) built on the regeneration system. Our studies are essential for successful genetic manipulation and genome editing for white clover and will assist in the functional characterization of genes associated with aesthetic quality and resistance.

\section{Abbreviations}

2,4-D: 2,4-dichlorophenoxy acetic acid; NAA: naphthalene acetic acid; 6-BA:6-benzyl amino purine; AS: acetosyringone; GUS: $\beta$-glucuronidase; Kan: kanamycin; Cef: Cefotaxime sodium salt; PPT: phosphinothricin; CCM: clover callus medium; CDM: clover differentiation medium; CRM: clover rooting medium; CIM: clover infection medium; CM: co-cultivation medium; CCM2-S: CCM2 selection medium; CDM2-S: CDM2 selection medium; CRM-S: CRM selection medium

\section{Declarations}

\section{Funding}

This work was supported by Tianfu Outstanding Scientist Program [NO.1863] and Sichuan Forage Innovation Team Program [NO. SCCXTD-2020-16].

\section{Competing interests}

The authors declare that they have no conflicts of interest. The funders had no role in the design of the study; in the collection, analyses, or interpretation of data; in the writing of the manuscript, or in the decision to publish the results.

\section{Author contributions}

YP, SB, and TJ conceived and designed the study, TJ and BC conducted the experiments, HF, MZI, and MJH provided advice, HF and ZL analyzed the data, and TJ wrote the manuscript. All authors read and approved the final manuscript.

\section{Data Availability}

The datasets used and/or analysed during the current study are available from the corresponding author on reasonable request.

\section{References}


1. Ahuja PS, Lu DY, Cocking EC \& Davey MR (1983) An assessment of the cultural capabilities of Trifolium repens L. (white clover) and Onobrychis viciifolia Scop. (sainfoin) mesophyll protoplasts. Plant Cell Reports 2(5):269-272 doi:10.1007/bf00269158

2. Amiri S \& Mohammadi R (2021) Establishment of an efficient in vitro propagation protocol for Sumac (Rhus coriaria L.) and confirmation of the genetic homogeneity. Sci Rep 11(1):173-173 doi:10.1038/s41598-020-80550-4

3. Arun M, Subramanyam K, Mariashibu TS, Theboral J, Shivanandhan G, Manickavasagam M \& Ganapathi A (2015) Application of sonication in combination with vacuum infiltration enhances the Agrobacterium-mediated genetic transformation in Indian soybean cultivars. Applied Biochemistry Biotechnology 175(4):2266-2287 doi:10.1007/s12010-014-1360-x

4. Benzle KA, Finer KR, Marty D, McHale LK, Goodner BW, Taylor CG \& Finer JJ (2015) Isolation and characterization of novel Agrobacterium strains for soybean and sunflower transformation. Plant Cell, Tissue and Organ Culture 121(1):71-81

5. Bhojwani SS (1981) A tissue culture method for propagation and low temperature storage of Trifolium repens genotypes. Physiologia Plantarum 52(2):187-190 doi:10.1111/j.13993054.1981.tb08491.x

6. Bhojwani SS \& White DWR (1982) Mesophyll protoplasts of white clover: Isolation, culture and organogenesis. Plant Science Letters 26(2):265-271 doi:10.1016/0304-4211(82)90100-6

7. Bond JE \& Webb KJ (1989) Regeneration and analysis of plants from stolon segments of Trifolium repens (white clover). Plant Science 61(1):119-125 doi:10.1016/0168-9452(89)90125-8

8. Chetty V, Ceballos N, Garcia D, Narváez-Vásquez J, Lopez W \& Orozco-Cárdenas M (2013) Evaluation of four Agrobacterium tumefaciens strains for the genetic transformation of tomato (Solanum lycopersicum L.) cultivar Micro-Tom. Plant Cell Reports 32(2):239-247

9. Christiansen P, Gibson JM, Moore A, Pedersen C, Tabe L \& Larkin PJ (2000) Transgenic Trifolium repens with foliage accumulating the high sulphur protein, sunflower seed albumin. Transgenic Research 9(2):103-113 doi:10.1023/a:1008967409302

10. Ding YL, Aldao-Humble G, Ludlow E, Drayton M, Lin YH, Nagel J, Dupal M, Zhao G, Pallaghy C \& Kalla $\mathrm{R}$ (2003) Efficient plant regeneration and Agrobacterium-mediated transformation in Medicago and Trifolium species. Plant Science 165(6):1419-1427 doi:10.1016/j.plantsci.2003.08.013

11. Ealing PM, Hancock KR \& White DW (1994) Expression of the pea albumin 1 gene in transgenic white clover and tobacco. Transgenic Research 3(6):344-354 doi:10.1007/bf01976766

12. Forster JW, Panter S, Mouradov A, Mason J \& Spangenberg GC (2013) Transgenic technologies for enhanced molecular breeding of white clover (Trifolium repens L.). Crop and Pasture Science 64(1):26-38 doi:10.1071/cp12184

13. Garcia C, de Almeida AAF, Costa M, Britto D, Valle R, Royaert S \& Marelli JP (2019) Abnormalities in somatic embryogenesis caused by 2, 4-D: an overview. Plant Cell, Tissue and Organ Culture 137(2):193-212 
14. Gresshoff PM (1980) In vitro culture of white clover: callus, suspension, protoplast culture, and plant regeneration. Botanical Gazette 141(2):157-164

15. Griffiths AG, Moraga R, Tausen M, Gupta V, Bilton TP, Campbell MA, Ashby R, Nagy I, Khan A, Larking A, Anderson C, Franzmayr B, Hancock K, Scott A, Ellison NW, Cox MP, Asp T, Mailund T, Schierup MH \& Andersen SU (2019) Breaking free: The genomics of allopolyploidy-facilitated niche expansion in white clover. Plant Cell 31(7):1466-1487 doi:10.1105/tpc.18.00606

16. Hamama L, Voisine L, Peltier D \& Boccon-Gibod J (2011) Shoot regeneration and genetic transformation by Agrobacterium tumefaciens of Hydrangea macrophylla Ser. leaf discs. Scientia Horticulturae 127(3):378-387 doi:10.1016/j.scienta.2010.09.021

17. Hansuek S, Liamnimitr N \& Khawniam T (2018) Effects of BA and NAA on plant regeneration of neck orange (Citrus reticulate Blanco). Technology 14(7):1225-1234

18. Hayta S, Smedley MA, Demir SU, Blundell R, Hinchliffe A, Atkinson N \& Harwood WA (2019) An efficient and reproducible Agrobacterium-mediated transformation method for hexaploid wheat (Triticum aestivum L.). Plant Methods 15(1) doi:10.1186/s13007-019-0503-z

19. Hayta S, Smedley MA, Li J, Harwood WA \& Gilmartin PM (2018) Agrobacterium-mediated transformation systems of Primula vulgaris. Plant Methods 14 doi:10.1186/s13007-018-0360-1

20. Hood EE, Gelvin SB, Melchers LS \& Hoekema A (1993) New Agrobacterium helper plasmids for gene transfer to plants. Transgenic Research 2(4):208-218

21. Islam A, Leung S, Burgess EPJ, Laing WA, Richardson KA, Hofmann RW, Dijkwel PP \& McManus MT (2015) Knock-down of transcript abundance of a family of Kunitz proteinase inhibitor genes in white clover (Trifolium repens) reveals a redundancy and diversity of gene function. New Phytologist 208(4):1188-1201 doi:10.1111/nph.13543

22. Jahufer M, Ford J, Widdup K, Harris C, Cousins G, Ayres J, Lane L, Hofmann R, Ballizany WL \& Mercer C (2012) Improving white clover for Australasia. Crop and Pasture Science 63(9):739-745 doi:10.1071/CP12142

23. Jenkins CLD, Snow AJ, Simpson RJ, Higgins TJ, Jacques NA, Pritchard J, Gibson J \& Larkin PJ (2002) Fructan formation in transgenic white clover expressing a fructosyltransferase from Streptococcus salivarius. Functional Plant Biology 29(11):1287-1298 doi:10.1071/fp02029

24. Jiang Q, Fu C \& Wang Z (2019) A unified Agrobacterium-mediated transformation protocol for Alfalfa (Medicago sativa L.) and Medicago truncatula. Methods in Molecular Biology 1864:153-163 doi:10.1007/978-1-4939-8778-8_11

25. Karadotcheva D, Vlahova M, Mihovsky Z, Alexandrova B \& Stoevska T (1995) In vitro culture and somatic embryogenesis of white clover (Trifolium repens L.). Biotechnology and Biotechnological Equipment 9(1):10-13 doi:10.1007/BF00265178

26. Konieczny R, Sliwinska E, Pilarska M \& Tuleja M (2012) Morphohistological and flow cytometric analyses of somatic embryogenesis in Trifolium nigrescens Viv. Plant Cell, Tissue and Organ Culture 109(1):131-141 doi:0.1007/s11240-011-0081-x 
27. Kumar T, Bao A-K, Bao Z, Wang F, Gao L \& Wang S-M (2018) The progress of genetic improvement in alfalfa (Medicago sativa L.). Czech Journal of Genetics and Plant Breeding 54(2):41-51 doi:10.17221/46/2017-CJGPB

28. Larkin PJ, Gibson JM, Mathesius U, Weinman JJ, Gartner E, Hall E, Tanner GJ, Rolfe BG \& Djordjevic MA (1996) Transgenic white clover. Studies with the auxin-responsive promoter, GH3, in root gravitropism and lateral root development. Transgenic Research 5(5):325-335 doi:10.1007/bf01968942

29. Martins JPR, Rodrigues LCdA, Silva TdS, Gontijo ABPL \& Falqueto AR (2020) Modulation of the anatomical and physiological responses of in vitro grown Alcantarea imperialis induced by NAA and residual effects of BAP. Ornamental Horticulture 26:283-297 doi:10.1590/2447-536X.v26i2.2138

30. McCurdy JD, McElroy JS \& Guertal EA (2013) White clover (Trifolium repens) establishment within dormant bermudagrass turf: Cultural considerations, establishment timing, seeding rate, and coolseason companion grass species. American Society for Horticultural Science 48(12):1556-1561 doi:10.21273/HORTSCI.48.12.1556

31. Mcmanus MT, Laing WA, Watson LM, Markwick N, Voisey CR \& White DWR (2005) Expression of the soybean (Kunitz) trypsin inhibitor in leaves of white clover (Trifolium repens L.). Plant Science 168(5):1211-1220 doi:10.1016/j.plantsci.2004.12.020

32. Mo R, Huang Y, Yang S, Zhang Q \& Luo Z (2015) Development of Agrobacterium-mediated transient transformation in persimmon (Diospyros kaki Thunb.). Scientia Horticulturae 192:29-37 doi:10.1016/j.scienta.2015.05.013

33. Mohapatra SS \& Gresshoff PM (1982) Ecotypic variation of in vitro plantlet formation in white clover (Trifolium repens). Plant Cell Reports 1(5):189-192 doi:10.1007/BF00270231

34. Mukherjee S, Ghosh B \& Jha S (2000) Enhanced forskolin production in genetically transformed cultures of Coleus forskohlii by casein hydrolysate and studies on growth and organisation. Biotechnology Letters 22(2):133-136

35. Murashige T \& Skoog F (1962) A revised medium for rapid growth and bio assays with tobacco tissue cultures. Physiologia Plantarum 15(3):473-497

36. Narancio R, Ding YL, Lin YH, Sahab S, Panter S, Hayes M, John U, Anderson H, Mason J \& Spangenberg G (2020) Application of linked and unlinked co-transformation to generate triple stack, marker-free, transgenic white clover (Trifolium repens L.). Plant Cell, Tissue and Organ Culture 142(3):635-646 doi:10.1007/s11240-020-01891-6

37. Oswald TH, Smith AE \& Phillips DV (1977) Callus and plantlet regeneration from cell cultures of Ladino clover and soybean. Physiologia Plantarum 39(2):129-134 doi:10.1111/j.13993054.1977.tb04023.x

38. Panter S, Chu PG, Ludlow E, Garrett R, Kalla R, Jahufer MZZ, Arbiza AD, Rochfort S, Mouradov A, Smith KF \& Spangenberg G (2012) Molecular breeding of transgenic white clover (Trifolium repens L.) with field resistance to Alfalfa mosaic virus through the expression of its coat protein gene. Transgenic Research 21(3):619-632 doi:10.1007/s11248-011-9557-z 
39. Parrott WA \& Collins GB (1983) Callus and shoot-tip culture of eight Trifolium species in vitro with regeneration via somatic embryogenesis of T. Rubens. Plant Science Letters 28(2):189-194 doi:10.1016/S0304-4211(83)80009-1

40. Pederson GA (1986) In vitro culture and somatic embryogenesis of four Trifolium species. Plant Science 45(2):101-104 doi:10.1016/0168-9452(86)90044-0

41. RamanaRao MV \& Veluthambi K (2010) Selectable marker elimination in the T 0 generation by Agrobacterium-mediated co-transformation involving Mungbean yellow mosaic virus TrAP as a nonconditional negative selectable marker and bar for transient positive selection. Plant Cell Reports 29(5):473-483 doi:10.1007/s00299-010-0836-6

42. Schmidt MA, Martin GS, Artelt BJ \& Parrott WA (2004) Increased transgene expression by breeding and selection in white clover. Crop Science 44(3):963-967 doi:10.2135/cropsci2004.9630

43. Sharma SB, Hancock KR, Ealing PM \& White DWR (1998) Expression of a sulfur-rich maize seed storage protein, $\delta$-zein, in white clover (shape Trifolium repens) to improve forage quality. Molecular Breeding 4(5):435-448

44. Sincik M \& Acikgoz E (2007) Effects of white clover inclusion on turf characteristics, nitrogen fixation, and nitrogen transfer from white clover to grass species in turf mixtures. Communications in Soil Science and Plant Analysis 38(13-14):1861-1877 doi:10.1080/00103620701435621

45. Vaseva I, Akiscan Y, Demirevska K, Anders I \& Feller U (2011) Drought stress tolerance of red and white clover-comparative analysis of some chaperonins and dehydrins. Scientia Horticulturae 130(3):653-659 doi:10.1016/j.scienta.2011.08.021

46. Voisey CR, White D, Mcgregor PG, Wigley PJ \& Chilcott CN Transformation of white clover with Bt genes. In: 2nd Canberra Meeting on Bacillus thuringiensis, 1993. p 75-83

47. Voisey CR, White DW, Dudas B, Appleby RD, Ealing PM \& Scott AG (1994) Agrobacterium-mediated transformation of white clover using direct shoot organogenesis. Plant Cell Reports 13(6):309-314 doi:10.1007/bf00232627

48. Webb KJ, Woodcock S \& Chamberlain DA (1987) Plant regeneration from protoplasts of Trifolium repens and Lotus corniculatus. Plant Breeding 98(2):111-118

49. Weissinger AK \& Parrott WA (1993) Repetitive somatic embryogenesis and plant recovery in white clover. Plant Cell Reports 12(3):125-128 doi:10.1007/bf00239091

50. Wen L, Chen Y, Schnabel E, Crook A \& Frugoli J (2019) Comparison of efficiency and time to regeneration of Agrobacterium-mediated transformation methods in Medicago truncatula. Plant Methods 15(1):20 doi:10.1186/s13007-019-0480-2

51. White DW (1984) Plant regeneration from long-term suspension cultures of white clover. Planta 162(1):1-7 doi:10.1007/bf00397413

52. White DW \& Greenwood D (1987) Transformation of the forage legume Trifolium repens L. using binary Agrobacterium vectors. Plant Molecular Biology 8(6):461-469 doi:10.1007/bf00017991

53. White DW \& Voisey C (1994) Prolific direct plant regeneration from cotyledons of white clover. Plant Cell Reports 13(6):303-308 doi:10.1007/bf00232626 
54. Williams WM, Verry IM, Ansari HA, Hussain SW, Ullah I \& Ellison NW (2019) A Eurasia-wide polyploid species complex involving $6 \times$ Trifolium ambiguum, $2 \times$ T. occidentale and $4 \times$ T. repens produces interspecific hybrids with significance for clover breeding. BMC Plant Biology 19(1):1-12 doi:10.1186/s12870-019-2030-5

55. Yamada T (1989) Selection of a highly-regenerative genotype of white clover (Trifolium repens L.) and plant regeneration from protoplasts derived from this genotype. Euphytica 44(3):181-186

56. Zaidi M, Narayanan M, Sardana R, Taga I, Postel S, Johns R, McNulty M, Mottiar Y, Mao J \& Loit E (2006) Optimizing tissue culture media for efficient transformation of different indica rice genotypes. Agronmy Research 4(2):563-575

\section{Figures}

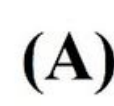

Cotyledons

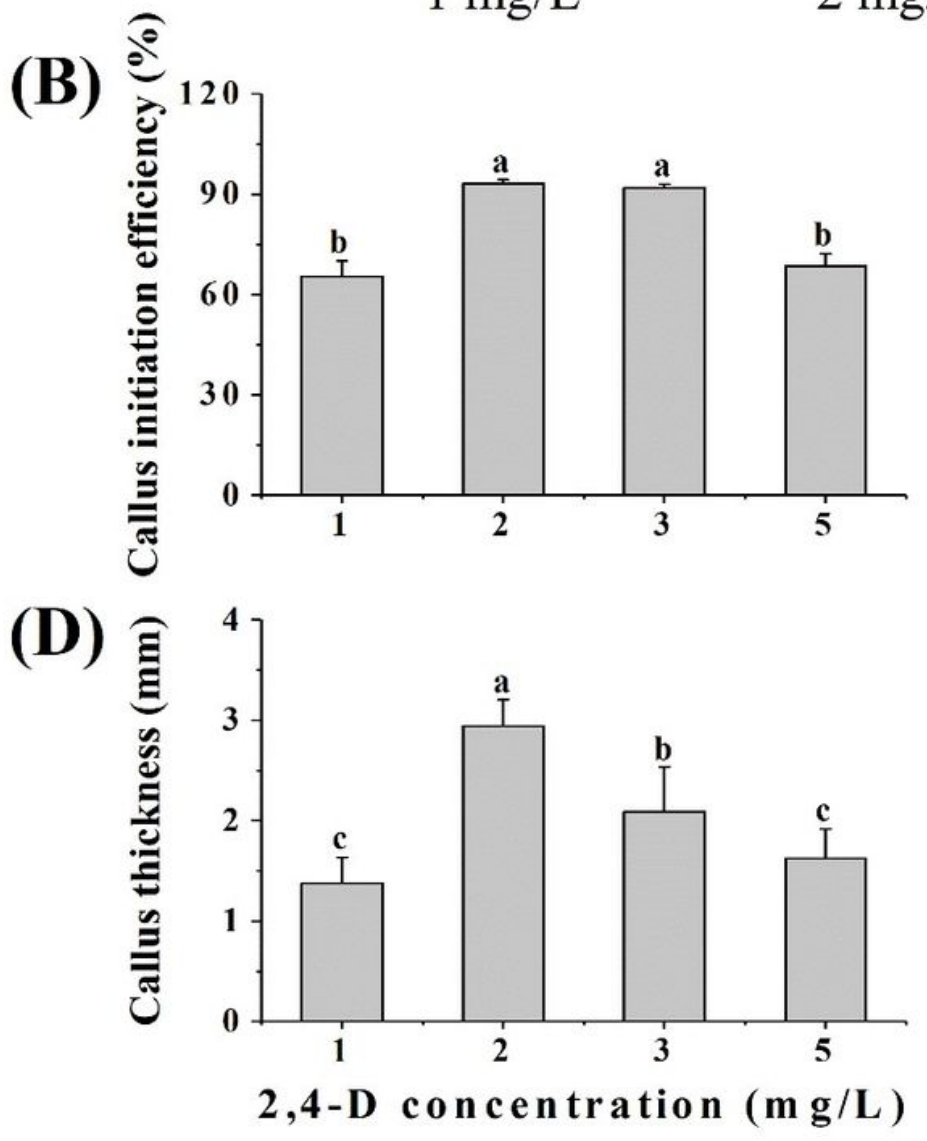

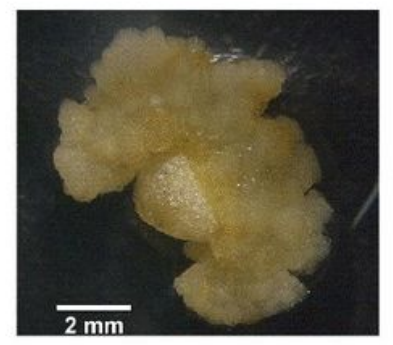

$2 \mathrm{mg} / \mathrm{L}$

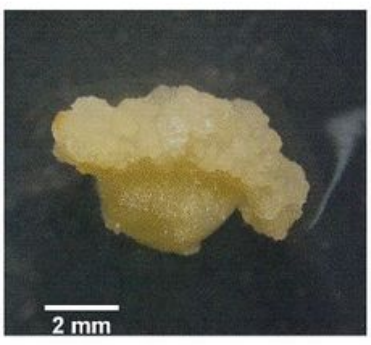

$3 \mathrm{mg} / \mathrm{L}$

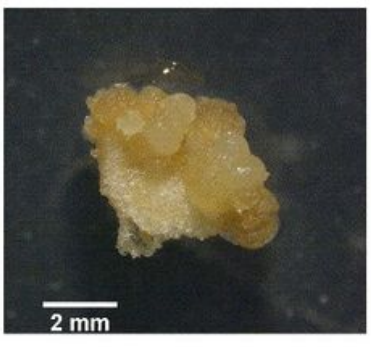

$5 \mathrm{mg} / \mathrm{L} 2,4-\mathrm{D}$

(C)

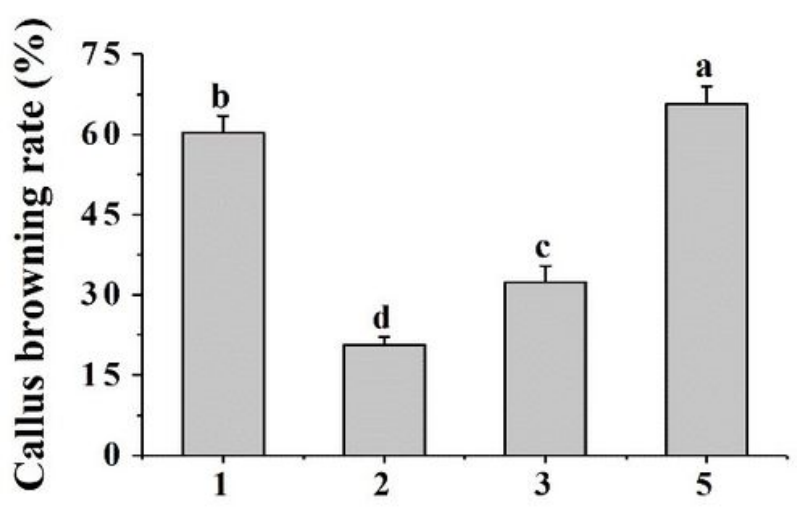

(E)

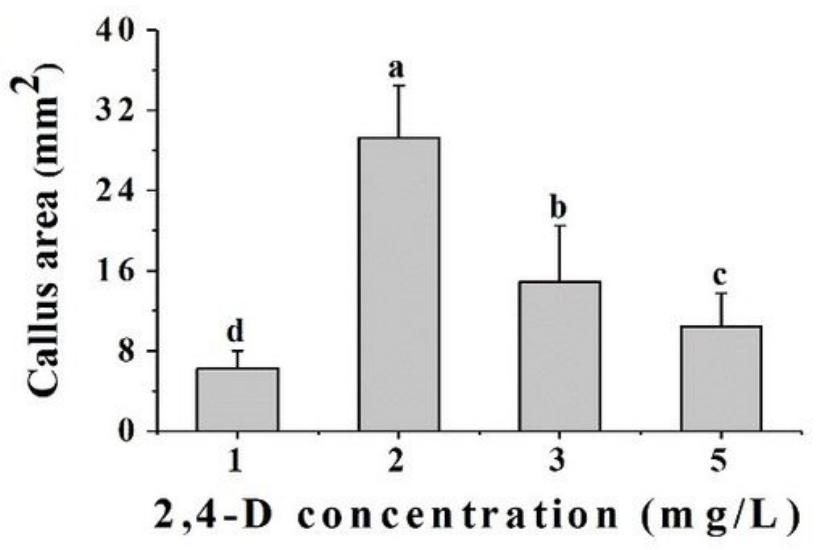

Figure 1 
Influence of induction media CCM1-CCM4 on the initiation and proliferation of callus from cotyledons explants. (A) The texture of callus on CCM medium with different quantities of 2,4-D. (B) Callus initiation efficiency after 20 days of cultivation. (C) callus browning rate, (D) callus thickness, and (E) callus area following 40 days of induction. Each treatment ( $A$ and $B$ ) comprised about 55 explants and was performed in 3 replicates. Data ( $D$ and $E$ ) were generated from 10 independent replicates. Different letters indicate statistically significant differences at $\mathrm{P}<0.05$.

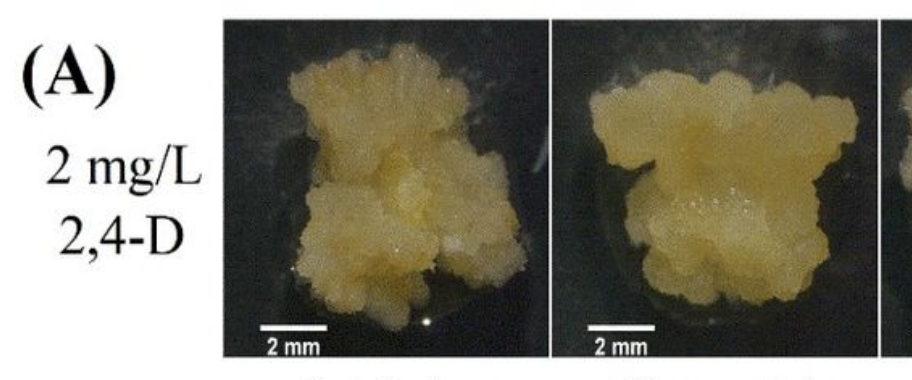

Cotyledons

Hypocotyls
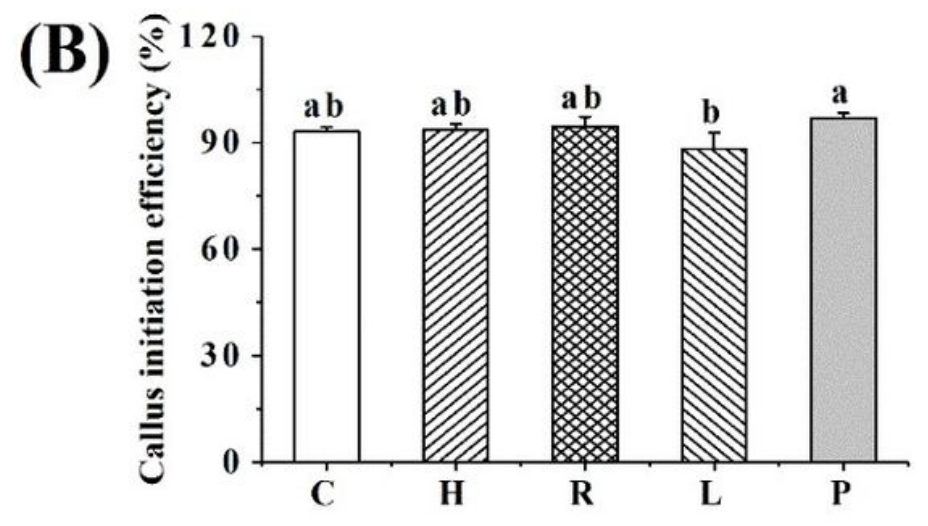

(D)

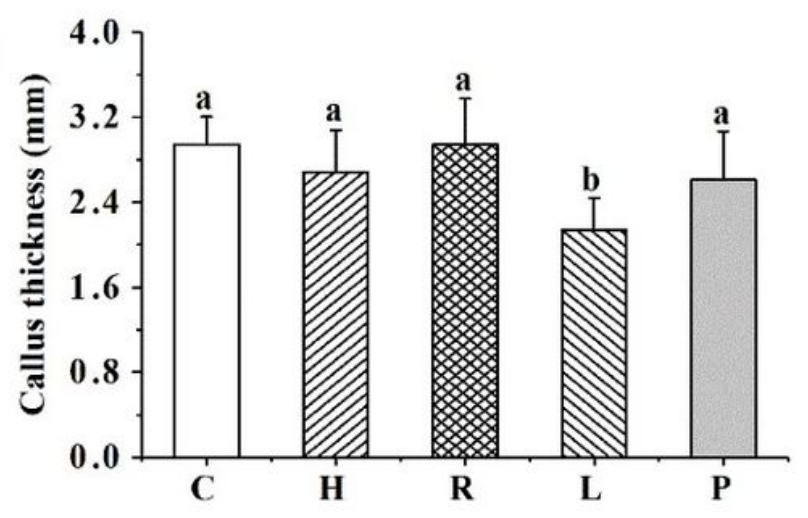

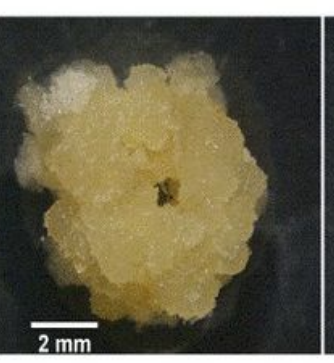

Roots

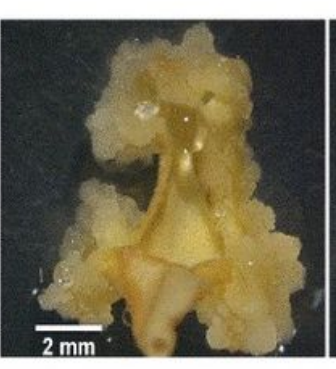

Leaves

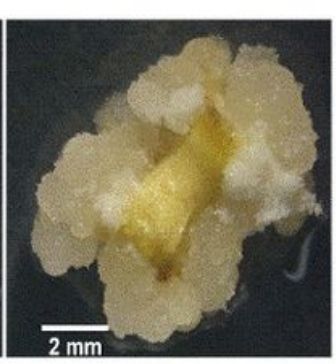

Petioles

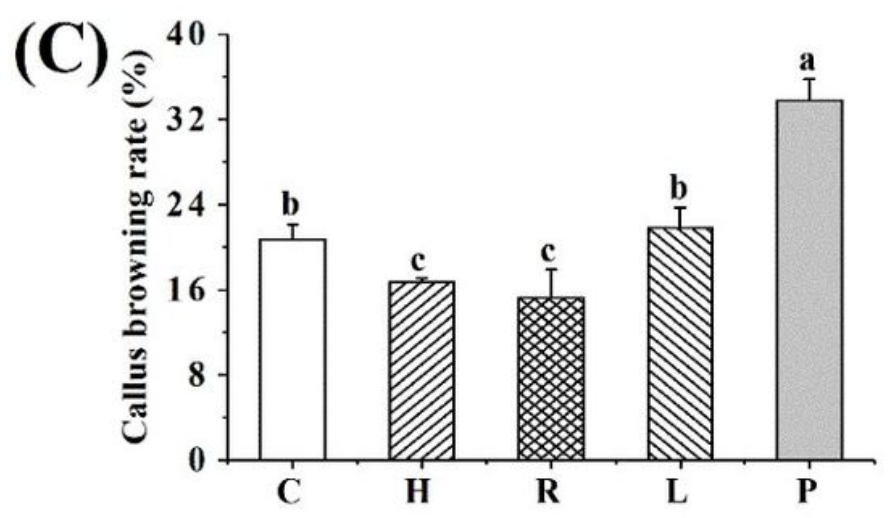

(E)

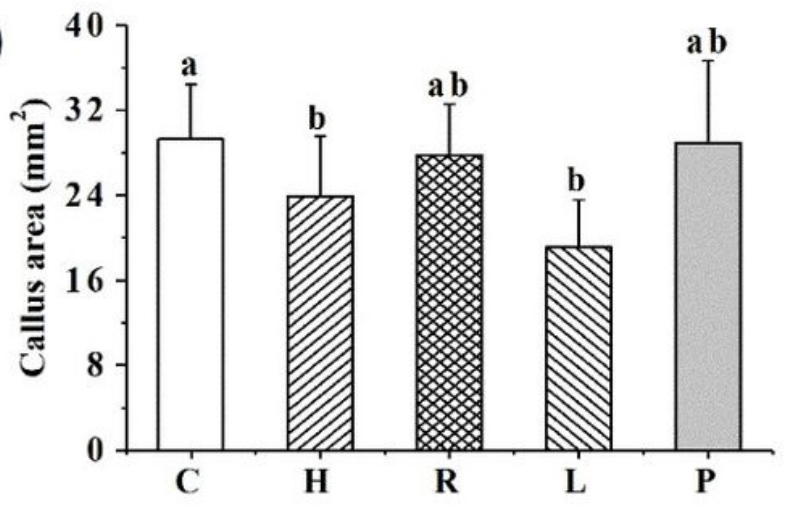

Figure 2

Effect of CCM2 medium on different explants. (A) Immature embryo-derived callus after 45 days culture on CCM2 from the cotyledons, hypocotyls, roots, leaves, and petioles explants. (B) Callus initiation efficacy after 20 days of induction. (C) callus browning rate, (D) callus thickness, and (E) callus area following 45 days of development. Each treatment (A and B) comprised about 60 explants and was 
performed in 3 replicates. Data ( $D$ and $E$ ) were generated from 10 independent replicates. Different letters indicate significant difference at $\mathrm{P}<0.05$. C: Cotyledons, H: Hypocotyls, R: Roots, L: Leaves, P: Petioles.

(A)

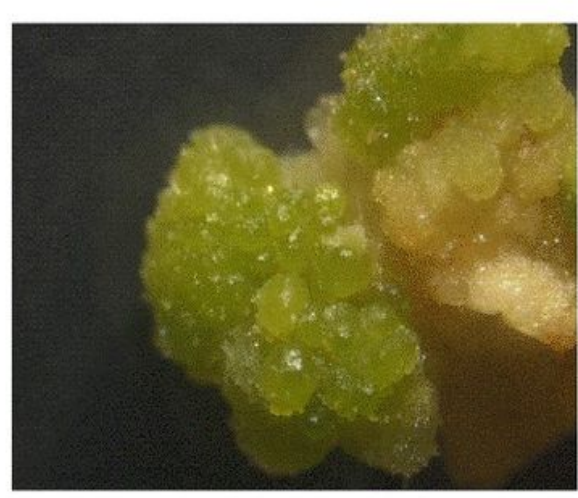

(C)

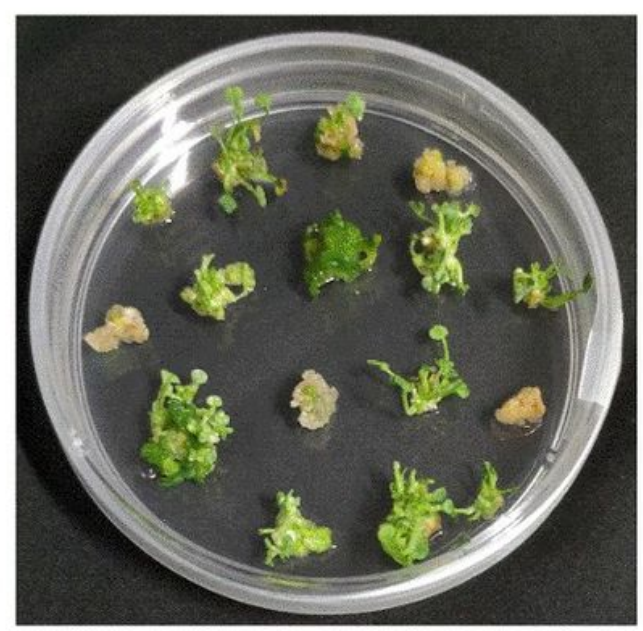

(B)

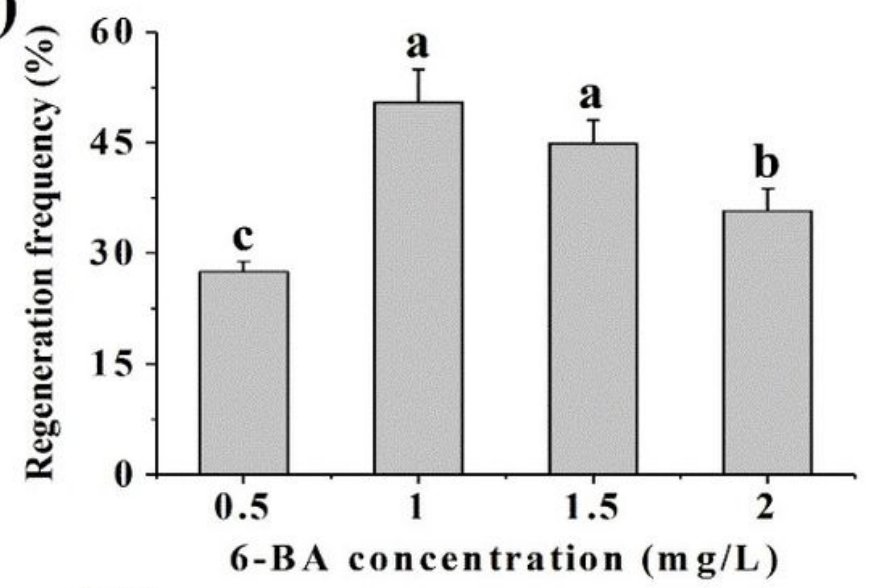

(D)

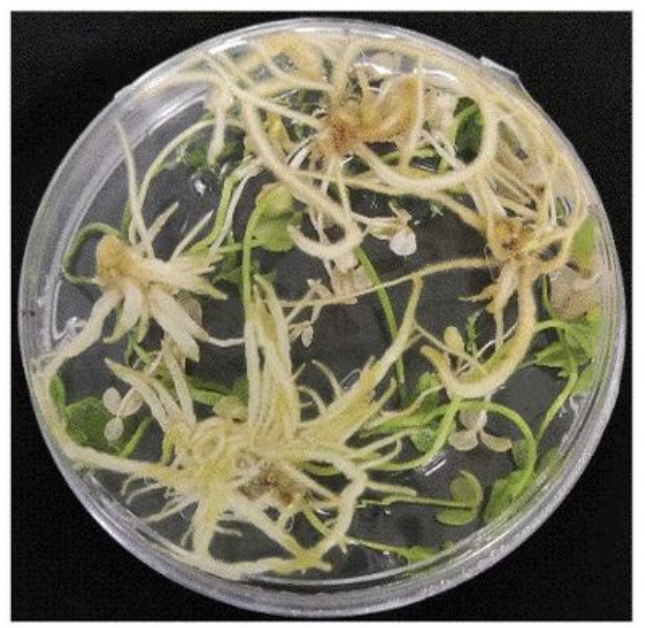

Figure 3

White clover plantlets regeneration from calluses. (A) The greening globular embryo after 7 days of differentiation. (B) Effect of 6-BA concentration on calluses regeneration frequency. (C) Trifoliate leaves sprouted from embryogenic callus after 50 days on CDM2. (D) Numerous roots were produced on CRM after 40 days of induction. Each treatment (B) comprised about 50 explants and was performed in 3 replicates. Different letters indicate significant differences at $P<0.05$. 
(A)

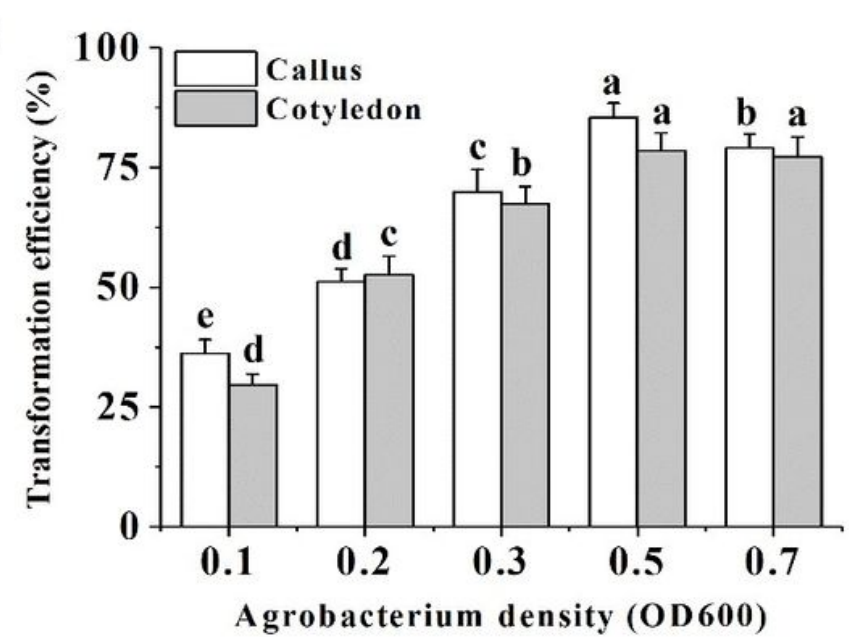

(C)

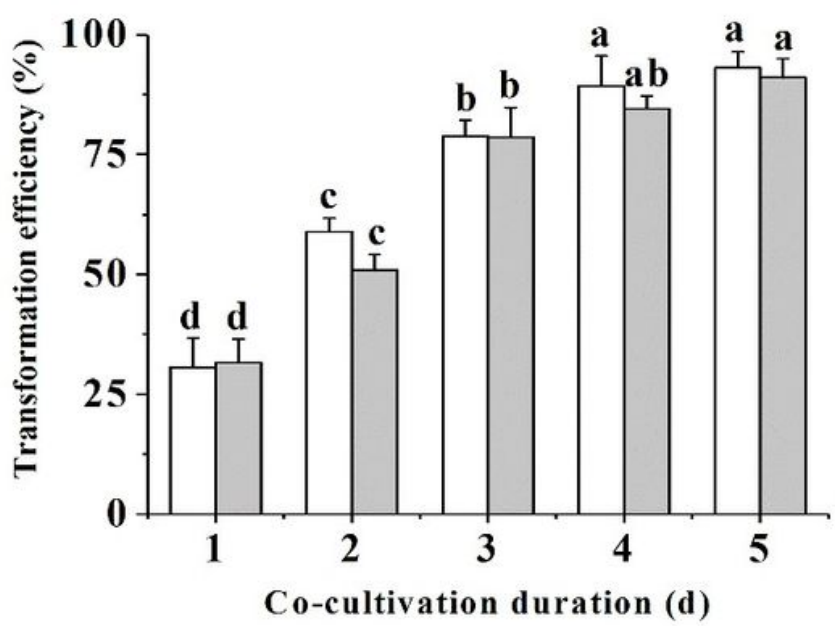

(B)

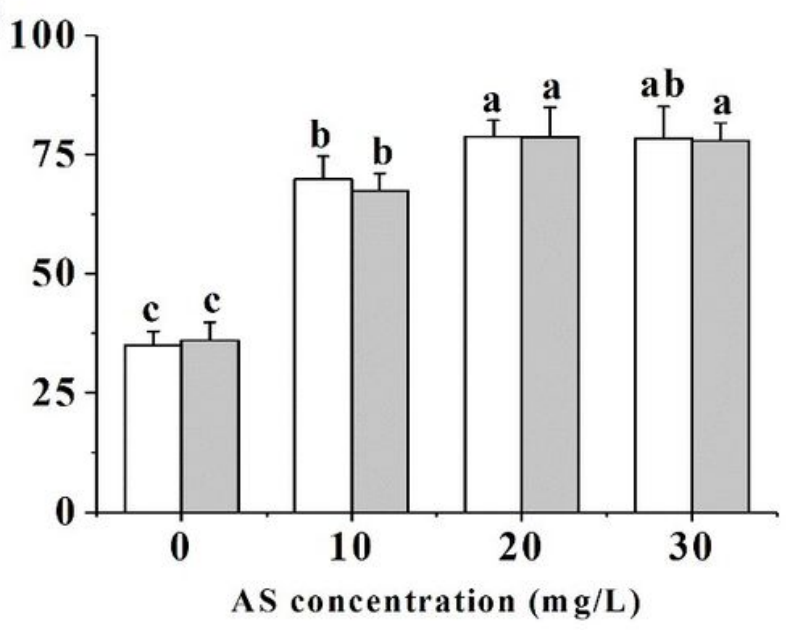

\section{Figure 4}

Effects of Agrobacterium concentration (A), AS concentration (B), and co-cultivation duration (C) on transient transformation efficiency. Each treatment comprised about 25 (calluses) or 35 (cotyledons) tissues, and the data were expressed as means \pm SD from three replicates. Different letters above the columns display a significant difference at $\mathrm{P}<0.05$. 

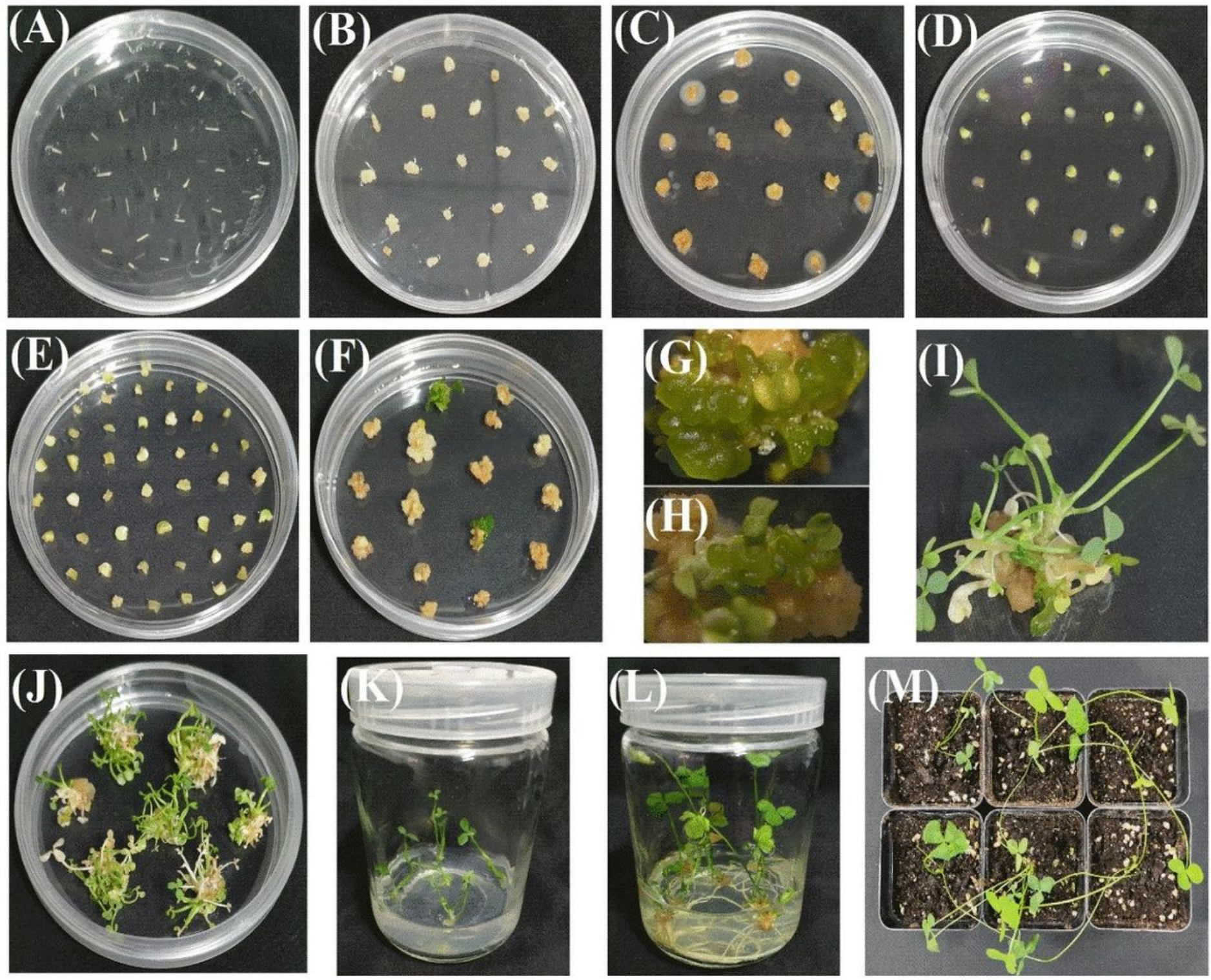

\section{Figure 5}

Transgenic white clover obtained through Agrobacterium-mediated transformation using Protocol $A$ and Protocol B. (A) White clover root segments isolated from 4-days-old seedlings. (B) Callus induced after 30 days from roots explants on CCM2. (C) Root-derived calluses after 4 days of co-cultivation with Agrobacterium. (D) Cotyledons explants co-cultured with Agrobacterium after 4 days. (E) Cotyledonderived calluses induced and selected on CCM2-S. (F) Established calluses transferred onto CDM2-S after 25 days. $(\mathrm{G})$ and $(\mathrm{H})$ Cotyledonary embryo formed from $(\mathrm{F})$. (I) and $(\mathrm{J})$ Proliferating kanamycin-resistant shoots after 60 days on CDM2-S. (K) Independent resistant plantlets transplanted on CRM-S for root development. (L) Rooted transgenic white clover regenerated from callus. (M) Regenerated plants in the soil. 

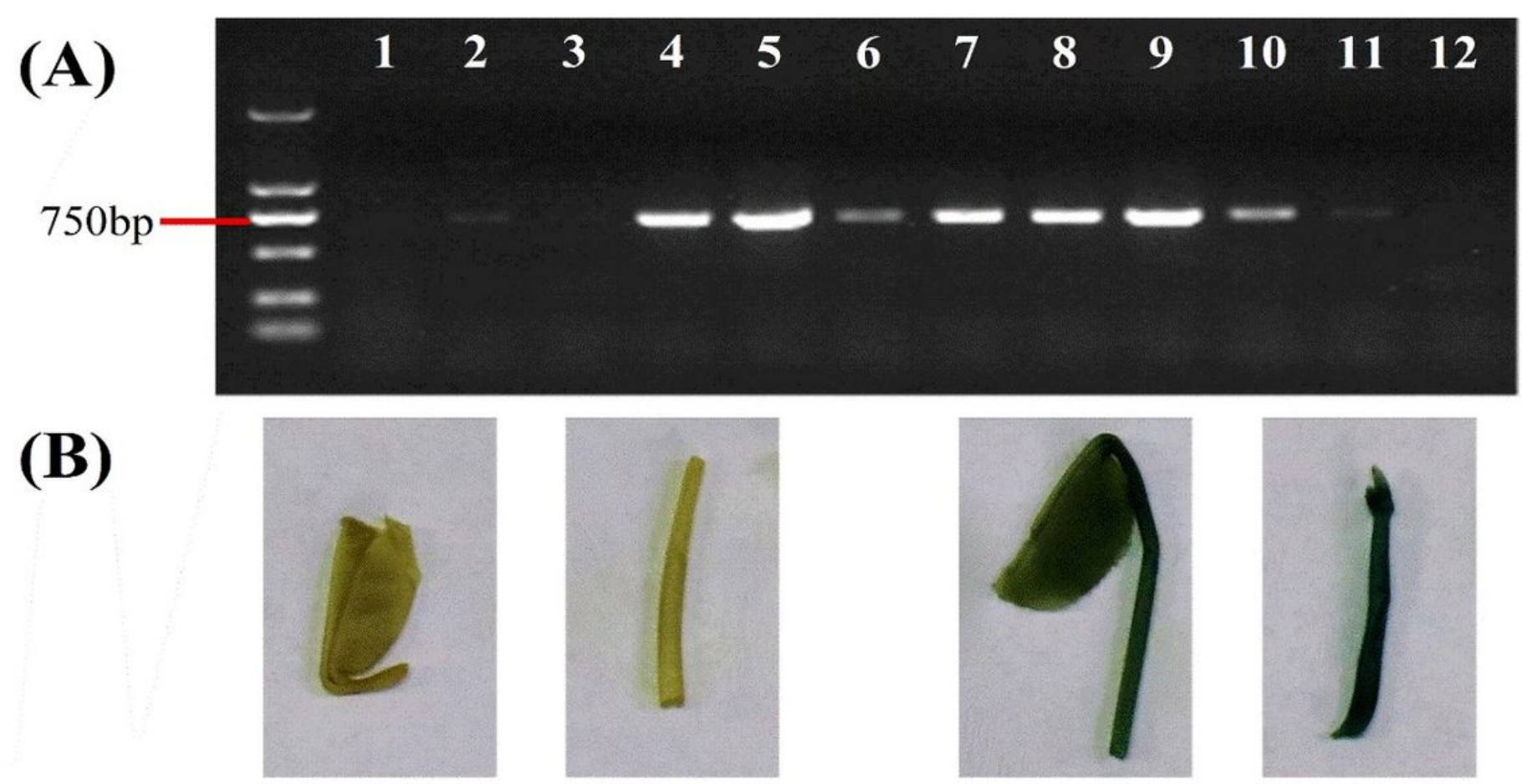

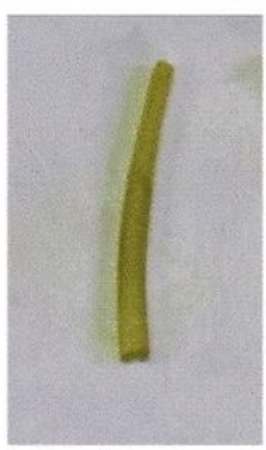

Control
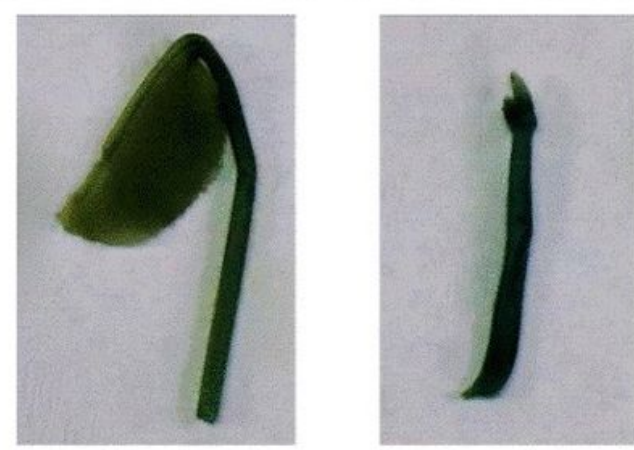

Transgenic white clover

\section{Figure 6}

Identification of positive transgenic white clover. (A) PCR amplification for NPTII gene.1: Non-transformed white clover (control). 4-10: Positive transgenic plants. 2-3,11-12: Negative white clover. (B) Histochemical GUS staining for control and positive transgenic white clover.

\section{Supplementary Files}

This is a list of supplementary files associated with this preprint. Click to download.

- SupplementaryMaterial.pdf 